\title{
Economic Growth and a Low Carbon Economy-Does the Earth Suffer from an "Easter Island Syndrome”?
}

\author{
Andreas Oberheitmann ${ }^{1,2,3}$ \\ ${ }^{1}$ Research Center for International Environmental Policy, School of Environment, Tsinghua University, Beijing, China; ${ }^{2}$ Rheinisch \\ Westfälisches Institut für Wirtschaftsforschung, Essen, Germany; ${ }^{3}$ Jiangnan University, Wuxi, China. \\ Email: oberheitmann@tsinghua.edu.cn
}

Received October $3^{\text {rd }}$, 2011; revised November $8^{\text {th }}$, 2011; accepted November $18^{\text {th }}, 2011$.

\begin{abstract}
The history of the Eastern Islands in the Pacific with an increasing over-utilization of natural resources reminds us of the mistakes modern societies are making and the question is obvious whether the Earth is suffering from an Eastern Islands Syndrome, in other words whether the egoism inherent in humans long-term might have fatal consequences for our species homo sapiens. Climate research identified two important phenomena, which should remind us of the Easter Islands: feedbacks and tipping points, i.e. self-accelerating phenomena of global warming and reaching irreversible points of climate change. Only a quick worldwide return to a low carbon economy is able to stabilize global warming on a bearable level. Both Annex-I countries and Non-Annex-I countries have to contribute to reaching this goal taking their historical, current and future responsibilities into account. A post Kyoto regime based on cumulative per-capita $\mathrm{CO}_{2}$-emission rights and an international emission trading could provide for incentives to achieve a low carbon economy, especially for newly industrialized countries.
\end{abstract}

Keywords: Climate Change, Feedbacks, Tipping Points, Per Capita Cumulative Emission Rights, Emission Trading

\section{Introduction}

When the Easter Islands were settled, is unclear. Older sources say $300 \mathrm{AD}$ - $400 \mathrm{AD}$, parallel to settling the Hawaiis, some newer sources are putting forward the time between $700 \mathrm{AD}$ - $800 \mathrm{AD}$. Since this time, a society with ten independent tribes developed living in different parts of the island, but without having clear borders. In the beginning, only the coastal regions were settled. Approximately by $1100 \mathrm{AD}$, the time of the advanced culture of the Easter Islands with the establishment of monumental architecture began. Among them the bestknown are the large stone statues (Moai), standing at the coast and looking into the island with their big eyes. This cultural bloom, however, only lasted to the mid 17th Century, at the latest then degeneration of the society of the Easter Islands began. But in the centuries before, there had been social phenomena such as the over-usage of natural resources already occurring, which should remind us of our own history and the effects of global climate change [1]. Does the egoism of humans, which is driving force of economic growth, long-term become a global calamity—does the Earth suffer from an "Easter Island Syndrome"? The history of the Easter Islands in the Pacific shows us this "tragedy of the commons" [2] in a nutshell.

Section 1 of this paper describes the history of the Easter Islands and raises the issue whether the Earth is suffering from an Easter Islands Syndrome. Climate research identified two important phenomena, which should remind us of the Easter Islands: feedbacks and tipping points (Section 2). Section 3 provides for lessons to be learned from the history of the Easter Islands, i.e. building a path to a low carbon economy. An international emissions trading system is proposed based on cumulative per-capita $\mathrm{CO}_{2}$-emission rights which might provide incentives to pursue this low carbon economy path especially in newly industrialized countries with an emission budget below the assumed threshold. Section 4 summarizes the article.

\section{History of the Easter Islands and Issues to Be Raised}

Up to the end of the 13th Century, the soil of the Easter 
Islands was used in a sustainable way, after then a radical deforestation began with increasing soil erosion. The growth of population and increasing settling in the interior island without access to the sea as an important source of food and as a consequence with a growing agricultural production were seen as the important factors for the deforestation.

This phenomenon, however, occurs world-wide. At the beginning of the industrial revolution, about 1750, world population was between 630 and 960 million [3]. In 2009, it was already 6.8 bn [4]. By 2050, world population is expected to reach $9 \mathrm{bn}$. The transformation of the land surface is probably the first considerable (although regional) influence, which humans had on the global climate. 1750 only about $8-9 \mathrm{Mill} \cdot \mathrm{km}^{2}$ or $6 \%-7 \%$ of the world land surface were agriculturally used, especially in Europe, India and China. In the year 1990, it already was $46-51 \mathrm{Mill} \cdot \mathrm{km}^{2}$ or $35 \%$ - 39\% of the land surface of the Earth. About $11 \mathrm{Mill} \cdot \mathrm{km}^{2}$ forest were cut. Today, deforestation is responsible for about a fifth of growth of net global anthropogenous $\mathrm{CO}_{2}$-emissions [5].

After $1425 \mathrm{AD}$, intensive agriculture with innovative measures (such as wall protected cultivated areas, stone mulch) was utilized on the Easter Islands: on the one hand because of the rising ground erosion, on the other hand due to the population growth as way out this Malthusian trap [6]. The intensive agriculture maintained until the first half of the 17th Century, when the tribal society collapsed.

The intensification of the agriculture with increasing capital-intensive means of production such as fertilizers, pesticides and machines, yielding an accordingly growing agricultural output per used land is also to be observed world-wide. Since the early 18th Century, sowing, reaping and threshing machines were invented and used first in England, which permitted to manage substantially larger agricultural fields. Justus Liebig's invention of the chemical fertilizer in 1840 and the increasing employment of these fertilizers on today world-wide 45 mill tons per year lead to a substantial increase of agricultural productivity [7]. Around 1900, one farmer could produce food for 4 other persons, 1950 one farmer nourished 10 persons, in 2004 already 143. Fossil energy consumption and the utilization of fertilizers on nitrogen basis and the related $\mathrm{CO}_{2}$ - and $\mathrm{N}_{2} \mathrm{O}$-Emissionen contribute to climate change. The contribution of the agriculture makes about 12.5 billion tons of $\mathrm{CO}_{2}$-equivalents per year or $28 \%$ of the approximately 45 billion tons of $\mathrm{CO}_{2}$-equivalents world-wide. With 2.1 billion tons of $\mathrm{CO}_{2}$-equivalents, the excessive use of fertilizers has thereby a considerable portion [5].

From archeo-biological investigations of waste of the settlements of the Easter Islands it is recognizable that the number and variety of sea-birds as source of food rapidly decreased after $1650 \mathrm{AD}$. On the basis of fossil discoveries back to 520 million years ago, also on a global scale, there is a long-term negative relation between global mean temperature and biodiversity. In times of higher temperatures the variety of types was smaller both in the sea and at the country then in times of lower temperatures. However, it is still unclear whether this is a causal relation.

Starting from the mid 17th Century, the monumental construction on the Easter Islands stopped. Starting from the end of the 17th, at the latest starting in the first half the 18th Century, the cult platforms were systematically destroyed by the people themselves and statues were thrown over. Finally, it came to a complete decline of the traditional culture.

Disputed is still, where the roots of this cultural decline are to be searched. Today, the majority of the researchers assume the problems were caused by the Islanders themselves. Some speaks for the fact that the substantial predatory exploitation of the inhabitants of their own natural resources on the island led to the disturbance of the ecological equilibrium and at the end to the decline of the society [1]. The question is what the history of the Easter Islands can teach us? Is the egoism of humans and their desire for more and more on a long-term basis fatal? Is the Earth on the edge of similar radical ecological changes due to the unrestrained consumption of fossil sources of energy and other resources?

\section{Climate Change Phenomena and the Easter Island Syndome: Feedbacks and Tipping Points}

The egoism and the desire for more is inherent in humans. In particular, if it has still little. One can feel that clearly here in China. The development of the economy at the expense of nature is at the agenda, all the more, the smaller the individual contribution for the negative total effect is. But on the other side, the hypothesis of the Environmental Kuznets Curve [8,9] may apply, that starting from a certain per capita income the utilization of the environment decreases again. The question is, whether the climate can bear per-capita greenhouse gas emissions converging to a certain level worldwide. It is very likely, that the answer is "no". Nowadays, "the limits to growth" actually have to be defined from an ecological view rather than as from the perspective of resource availability.

Climate research identified two important phenomena, which should remind us of the Easter Islands: feedbacks and tipping points [5].

Some effects of the global warming produce additional global warming, they work as feedbacks to the global 
climatic system. Some feedbacks are negative, i.e. warming effect induce cooling effects. Others are positive, so that global warming is accelerated. e.g., for the 1960's, the mean temperature in Siberia increased by around $3^{\circ} \mathrm{C}$, which leads to a deicing of the perma-frost soils since approximately ten years. Very large quantities of methane, which are bound below the perma-frosted ground as gas hydrates, now escapes into the atmosphere. Since methane is a greenhouse gas 21-times stronger than carbon dioxide, global warming is accelerated and even more perma-frost thaws off. On a long-term basis, something similar is true for a warming up of the oceans and the danger of a slow, uncontrollable and over centuries continuing methane release due to heated up deeper ocean layers. Even more important, however, is the short-term decrease of the sea ice, which covers up to 15 percent of the world's oceans. The oceans have a smaller reflecting ability (albedo) of sunlight than the ice surfaces, because they are darker. The oceans thus absorb a majority of the arriving sunlight, while the sea ice reflects up to $90 \%$ of the irradiated solar power in the universe. If the surface of the sea ice decreases, more solar power will be absorbed and the Earth warms up even more strongly. Among other things, due to the decrease of the sea ice and snow, the annual average temperature of the Arctic increased nearly twice as fast as in the remaining world. According to different projections, the Arctic will warm up around further $4^{\circ} \mathrm{C}$ to $7^{\circ} \mathrm{C}$ in the next 100 years [5].

If climate change continues, so-called tipping-points can be reached, at which the climate abruptly and irreversibly reacts. When these points will exactly be reached, is still uncertain. The tipping point for an ice-free Arctic in the summer, however, could already be very close. Global warming in connection with cutting rain forest could also lead to a tipping point, where the ecological system rain forest drains and completely breaks down finally. This would have substantial effects for the global climate, since less and less carbon dioxide can be absorbed and escapes into the atmosphere. Other tipping points exist approximately with the acidification of the oceans or to begin of the monsoon in India [10].

\section{Lessons to Be Learned from the History of the Easter Islands: Building a Path to a Low Carbon Economy}

The question, which arises last, is: what can we learn from the history of the Easter Islands? The most important device would be that we may not make the same mistakes on a global scale, which the inhabitants of the Easter Islands had made before us. Otherwise, possibly history repeats itself in a fatal way. Hardin described this tragedy by a pasture shared by local herders [2], called a commons. The herders are assumed to wish to maximize their yield, and so will increase their herd size whenever possible. The utility of each additional animal has two components, a positive and a negative. Tragically, the division of these costs and benefits is unequal: the individual herder gains all of the advantage, but the disadvantage of the incremental degradation of the pasture is shared among all herders using the pasture. Consequently, for an individual herder the rational course of action is to continue to add additional animals to his herd. However, since all herders reach the same rational conclusion, overgrazing with immediate losses occurs, and degradation of the pasture may be its long-term fate.

As for the utilization of fossil fuels and related costs of climate change it is quite similar. The single economic entity gets the full utility from using fossil fuels, e.g. by driving a new fossil fuelled car, but the costs of climate change are shared globally. This effect is the stronger the smaller the individual contribution to climate change and the larger the perceived absorption capacity of the atmosphere and thus the smaller the probability and costs of climate change are perceived by the economic entity. In fact, the costs of climate change are increasing, maybe even per capita with a growing world population, as greenhouse gases are continuously piling up in the atmosphere. But the marginal climate change costs still do not outweigh the marginal utility from contributing to climate change. This may be only the case, if one or more of the tipping points mentioned above are reached and climate change costs increase tremendously, literally from one year to the other. But then, it may be too late.

The problem with the long-lasting and cumulating greenhouse gases is that we (more or less) only can make climate change not worse. So, what to do? Technically, it is relatively clear. The establishment of a low carbon economy almost entirely using renewable energies should be the goal of all societies. This would enable the world to achieve an almost $\mathrm{CO}_{2}$-neutral economy for the future. Other greenhouse gases such as methane, laughing gas or fluorocarbon connections, however, are there by not yet from the atmosphere. They have to be abandoned as well, but a large step would be done achieving it with $\mathrm{CO}_{2}$. The opportunity to rewind history is only with "negative" emissions, i.e. a carbon capture and storage (CCS) of emissions from bio-fuels. The biomass "filled into the tank" represents carbon taken out of the atmosphere. If there are no emissions to the atmosphere during combustion as they are captured and stored, the net-emissions are negative. However, this approach is still very costintensive.

Under the current (a) energy price and (b) climate cost conditions, the "Easter Island Syndrome" is still virulent. The political task is to internalize the external effects of climate change into the energy price calculus of the eco- 
nomic entities and to make the expected climate costs more transparent or visible on an individual level. The instruments to do that on the national level are wellknown (taxes, subsidies, Coase-solutions etc.) or the government simply imposes regulatory command and control measures. The expected climate costs can be made more transparent through the publication of research results, e.g. in the IPCC framework. However, the problem still is that the government can only change the framework conditions, but not the people.

Even, if that worked on a national scale, there is the international dimension of the problem. As for climate change mitigation, it is extremely important to have a global approach, since under the current energy price conditions, the incentives are too large to deviate from a $\mathrm{CO}_{2}$-neutral path regionally and to keep on using coal, oil or gas to maintain or develop a competitive advantage over low-carbon economies. This is the expression of the "Easter Island Syndrome" on the international level.

Here, the international climate negotiations have to achieve a global consensus on binding greenhouse gas emission reduction targets in the post-Kyoto phase. A $2^{\circ} \mathrm{C}$ global temperature increase above pre-industrial levels is internationally accepted as having only minor implications for the economies and the environment. In 2007, the Environment Council of the European Union has confirmed this as the EU's indicative target [11]. For achieving the $2^{\circ} \mathrm{C}$ target with a probability of more than $60 \%$, greenhouse gas concentrations need to be stabilized at $450-400 \mathrm{ppm} \mathrm{CO}_{2}$-equivalent by 2100 , if the $90 \%$ uncertainty range for climate sensitivity is believed to be $1.5^{\circ} \mathrm{C}$ to $4.5^{\circ} \mathrm{C}[12]$.

On the average of 2008-2012, the Kyoto Protocol is pledging a $5.2 \%$ reduction of greenhouse gases against 1990, but much more far reaching obligations have to be taken. To achieve the $2^{\circ} \mathrm{C}$ target, by 2050, worldwide $\mathrm{CO}_{2}$-emissions have to be reduced by about $50 \%$, by the Annex-I countries on the average by $80 \%$.

One question among many is, how to distribute the $\mathrm{CO}_{2}$-emission targets among the single countries. Currently, different post-Kyoto approaches are discussed, including "per capita convergence in emission endowments", "soft landing in emission growth", "global preference score approach", "historical contribution to climate change or 'Brazilian proposal'”, "ability to pay”, or the "multi-stage approach". The main weakness of all these approaches is that at the same time

They do not take into the fact into consideration, that on the one side, the developed countries are responsible for the current $\mathrm{CO}_{2}$-concentration in the atmosphere, on the other side developing countries such as China and India are to a large extent responsible for the current additional $\mathrm{CO}_{2}$-emissions which now start to accumulate in the atmosphere (which is partly done in the "Brazilian proposal"), and do not provide for a fair distribution of emission rights like in "per capita convergence in emission endowments".

As $\mathrm{CO}_{2}$-concentration is cumulated emission over time, a post Kyoto regime should take this as a basis.

A post-Kyoto approach based on cumulated per capita $\mathrm{CO}_{2}$-emission rights would take the above mentioned weaknesses into account [13]. Here, the cumulated $\mathrm{CO}_{2}{ }^{-}$ emissions $\left(\mathrm{CO}_{2, \text { cum }}\right)$ of country $m$ are:

$$
\begin{aligned}
& \mathrm{CO}_{2, m, \text { cumcap }, t}=\sum_{t=1750}^{n} \mathrm{CO}_{2, \text { coal }, t, m}+\mathrm{CO}_{2, \text { oil }, t, m}+\mathrm{CO}_{2, \text { gas }, t, m} \\
& +\mathrm{CO}_{2, \text { bunker }, t, m}+\mathrm{CO}_{2, \text { flagas }, t, m}+\mathrm{CO}_{2, \text { cement }, t, m}
\end{aligned}
$$

The cumulated $\mathrm{CO}_{2}$-emissions per capita of country $m$ are:

$$
\mathrm{CO}_{2, m, \text { cumcap }, t}=\frac{\mathrm{CO}_{2, m, \text { cum }, t}}{\operatorname{POP} m, 2007}
$$

In order to make sure that a growing population does not lead to an increase of $\mathrm{CO}_{2}$-emission rights, the allocated cumulated per capita $\mathrm{CO}_{2}$-emissions from 1750 are based on the 2007 world population. A growing population over time, should not lead to an increase of $\mathrm{CO}_{2}$-emissions, but to an incentive to increase energy efficiency (or possibly to adopt a pro-active population growth policy, but this has to be considered in ethical terms).

The target would be the stabilization of global warming to 2 degree Celsius or 400 - 450 ppm $\mathrm{CO}_{2}$-concentration in the atmosphere. Calculating the cumulative $\mathrm{CO}_{2}$ emissions as a proxy for the $\mathrm{CO}_{2}$-concentration in the atmosphere, a concentration of $400 \mathrm{ppm} \mathrm{CO}_{2}$ represents about 1600 bn. $t$ cumulated $\mathrm{CO}_{2}$-emissions $\left(\mathrm{CO}_{2, \text { cum }}\right)$. Taking the 2007 world population (6552 Mill) as the constant reference over time, every human on Earth would have emission rights of $246 t \mathrm{CO}_{2 \text {,cumcap }}$ for the $400 \mathrm{ppm}$ concentration or $354 t \mathrm{CO}_{2, \text { cumcap }}$ for the 450 ppm concentration.

The Annex-I countries, on the average had to reduce their cumulated $\mathrm{CO}_{2}$-emissions per capita to their 1950 level instead of facing a further increase. In 2008, that would have meant to reduce per-capita cumulated emissions from $657 t \mathrm{CO}_{2, \text { cumcap }}$ by $411 t \mathrm{CO}_{2, \text { cumcap }}$ to $246 t$ $\mathrm{CO}_{2, \text { cumcap }}$. China would e.g. reach the $400 \mathrm{ppm}$ threshold by between 2026 (BAU), by 2025 (HIGH) and by 2033 (LOW) depending on the GDP-growth assumption in the model [13]. e.g., India, Indonesia, African and other Low Income Countries would not reach this threshold even by 2050 and could sell emission rights to the international market and finance the development of a low carbon economy.

The new distribution system itself is nor able to solve 
the problem of climate change mitigation itself or the "Eastern Island Syndrome", but it may help to reduce frictions in international climate protection cooperation. The success of such a system still heavily depends on the quality of monitoring, reporting and verification of energy consumption and greenhouse gas emissions worldwide and finally that the emission caps are kept on a global scale based on a responsibility that every human being feels for the whole. For that, however, the human nature has to change. The question is: can we change based on enlightened self-interest or do we have to learn it in a hard way?

\section{Summary}

The history of the Eastern Islands in the Pacific with an increasing over-utilization of natural resources reminds us of the mistakes modern societies are making and the question is obvious whether the egoism inherent in humans long-term might have fatal consequences for our species homo sapiens as it was for the population of the Easter Islands.

Climate research identified two important phenomena, which should remind us of the Easter Islands: feedbacks and tipping points, i.e. self-accelerating phenomena of global warming and reaching irreversible points of climate change. Only a quick worldwide return to a low carbon economy is able to stabilize global warming on a bearable level. Both, Annex-I countries and Non-Annex-I countries have to contribute to reaching this goal taking their historical, current and future responsibilities into account.

A post Kyoto regime based on cumulative per-capita $\mathrm{CO}_{2}$-emission rights and a international emission trading could provide for incentives to achieve a low carbon economy, especially for newly industrialized countries. This could be a step towards tackling climate change long term, the issue of the other greenhouse gases, however, also have to be addressed in the future.

\section{REFERENCES}

[1] J. Diamond, "Collapse: How Societies Choose to Fail or Succeed,” Viking Press, New York, 2005.

[2] G. Hardin, "The Tragedy of the Commons," Science, Vol. 162, No. 3859, 1968, pp. 1243-1248. doi:10.1126/science.162.3859.1243

[3] US Census Bureau, "Historical Estimates of World Population,” 2010. http://www.census.gov/ipc/www/wor ldhis.html

[4] Population Division of the Department of Economic and Social Affairs of the United Nations Secretariat, "World Population Prospects: The 2008 Revision,” United Nations, New York, 2008.

[5] IPCC, “Climate Change 2007," Synthesis Report. Contribution of Working Groups I, II and III to the Fourth Assessment Report of the Intergovernmental Panel on Climate Change, Geneva, 2007.

[6] T. R. Malthus, "An Essay on the Principle of Population as It Affects the Future Improvement of Society, with Remarks on the Speculations of Mr. Godwin, M. Condorcet, and Other Writers,” J. Johnson, London, 1798.

[7] Handelsblatt, "Absatz: Düngerproduzent $K+S$ Spürt Belebung der Kalinachfrage,” Verlagsgruppe Handelsblatt, Düsseldorf, 2010.

[8] G. Grossmann and A. Krueger, "Environmental Impacts of a North American Free Trade Arrangement," Discussion Papers in Economics, No. 158, Woodrow Wilson School of Public and International Affairs, Princeton, 1991.

[9] G. Grossmann and A. Krueger, "Economic Growth and the Environment," Quarterly Journal of Economics, Vol. 110. No. 2, 1995, pp. 352-377. doi:10.2307/2118443

[10] T. M. Lenton, H. Held, E. Kriegler, J. W. Hall, W. Lucht, S. Rahmstorf and H. J. Schellnhuber, "Tipping Elements in the Earth's Climate System," Proceedings of the National Academy of Sciences, Vol. 106, No. 6, 2008, pp. 1786-1793. doi:10.1073/pnas.0705414105

[11] European Commission, "Limiting Global Climate Change to 2 Degrees Celsius-The Way Ahead for 2020 and Beyond," Communication of the Commission to the Council, the European Parliament, the European Economic and Social Committee and the Committees of the Regions, Commission of the European Communities, Brussels, 2007.

http://eur-lex.europa.eu/LexUriServ/LexUriServ.do?uri= COM:2007:0002:FIN:EN:PDF

[12] M. Meinshausen, N. Meinshausen, W. Hare, S. Raper, K. Frieler, R. Knutti, D. Frame and M. Allen, “Greenhousegas Emission Targets for Limiting Global Warming to $2^{\circ} \mathrm{C}$," Nature, Vol. 458, 2009, pp. 1158-1163. doi:10.1038/nature08017

[13] A. Oberheitmann, “A New Post-Kyoto Climate Regime Based on Per-Capita Cumulative Emissions Rights-Rationale, Architecture and Quantitative Assessment of the Implication for the $\mathrm{CO}_{2}$-Emissions from China, India and the Annex-I Countries by 2050," Mitigation and Adaptation Strategies for Global Change, Vol. 15, No. 2, 2010, pp. 137-168. doi:10.1007/s11027-009-9207-4 